\title{
Antiretroviral treatment default and associated factors among people living with HIV/AIDS in Ayder Referral Hospital, Tigray, Ethiopia
}

\author{
Girmay Kalayu' ${ }^{1}$ Zewdneh Tomas ${ }^{2}$ \\ ${ }^{1}$ Department of Biology, Aksum University, Tigray, Ethiopia \\ ${ }^{2}$ Department of Biology, Wolaita Sodo University, Ethiopia
}

\begin{abstract}
Introduction: Antiretroviral therapy has turned HIV/acquired immunodeficiency syndrome (AIDS) from lethal to manageable chronic disease. However, treatment defaulting is a prominent challenge in development of drug resistance and eventually, leads to treatment failure. The aim of this study was to assess the prevalence of defaulting and associated factors among people living with HIV/AIDS (PLWHA) in the Ayder Referral Hospital, Tigray.

Material and methods: Defaulters were individuals who failed to take medication two or more doses in a single clinical appointment. Retrospective cohort study was employed to obtain socio-demographic data and the status of ART use among PLWHA in the study hospital. Semi-structured interview was conducted to obtain data on factors associated with defaulting treatment. In-depth focused group discussion was done with those who attended subsequent conversations made at the hospital. Telephone call was performed to those who were reluctant to attend the discussions.

Results: Data were presented using simple descriptive statistics. Of 240 patients who initiated ART, $160(66.6 \%)$ were active users and $80(34 \%)$ had missed more than one clinical appointment. Out of those $80,58(24.16 \%)$ were defaulters and $22(9.16 \%)$ died. Self-referral to other hospital, lack of food, social stigma, spiritual healing, and loss of interest in medication were the commonest reasons for defaulting ART medication. Tracing was not successful due to incorrect address at the register in $12(21 \%)$ of the defaulters..

Conclusions: Socio-economic factors appear to be the root of all reasons associated with ART default. ART clinic staffs should make sure that the address given at the register is genuine to facilitate adherence assessment.
\end{abstract}

HIV AIDS Rev 2021; 20, 1: 21-25 DOI: https://doi.org/10.5114/hivar.2021.105109

Key words: adherence, anti-retroviral-treatment, default, HIV/AIDS, PLWHA, social stigma.

Address for correspondence: Girmay Kalayu, Department of Biology, Aksum University, Tigray, Ethiopia,

e-mail: Gkalayu@gmail.com
Article history:

Received: 21.02.2020

Received in revised form: 06.04.2020

Accepted: 01.09.2020

Available online: 30.03 .2021
International Journal of HIV-Related Problems

HIV \& AIDS

R e vi e w 


\section{Introduction}

Despite a considerable increase of human immunodeficiency virus (HIV)/acquired immunodeficiency syndrome (AIDS) interventions in the millennium development goals (MDGs) period, the epidemic remains high in Ethiopia. In 2016, an estimated 670,906 people living with HIV were registered, with all ages and sexes in Ethiopia. The reemergence of HIV/AIDS in Ethiopia could be due to a low coverage of high impact interventions [1]. The same study reported that an estimated 1.1 million AIDS related disability-adjusted life years lost (DALY) were registered in Ethiopia in 2016.

Access to antiretroviral treatment (ART) has been shown to improve the quality of life of people living with HIV/AIDS (PLWHA) [2], and has led to a reduction in mortality and morbidity in developing countries [3-6]. The intention of ART program is to reduce viral replication, reduce HIV-related morbidity and mortality, and enhance quality of life of PLWHA [7]. Development of various ARTs have contributed to ART becoming a central strategy for HIV/AIDS control in Ethiopia [8]. In areas with limited access to ART, the hope of survival for PLWHA is very discouraging [3].

It is not uncommon that patients experience difficulty in following treatment recommendations. Given the global efforts towards expanding access to ARTs, the cause for default remains a subject of research. While patients are expected to remain on this life-long therapy, default continues to be a major concern. A mathematical modeling study [9] in sub-Saharan Africa estimated that, by 2030, the range of patients receiving antiretroviral therapy will remain constant, and the number of patients receiving second-line ART will rise to $6.6-19.6 \%$. The same study reported that the proportion of people receiving ART by 2014 in Ethiopia were 46\%. Treatment defaulting is thought to play a key factor in the development of drug resistance and treatment failure [10]. Defaulting also reduces immunological role of ART and results in AIDS-linked mortality and morbidity [11].

Poor adherence to ART treatment, among others, is a predictor for virological failure or drug resistance [12-17]. So far, extensive features and short-term treatment default were not studied adequately. Still, studies have estimated that maintaining ART adherence above 95\% is the required level of drug adherence for sustained viral suppression [14, 16, $18,19]$. In terms of total missed appointments, greater than three days per month is considered as poor adherence [12]. Therefore, a patient who missed more than one clinical appointment needs to be incorporated in this study. Hence, this study was intended to assess the prevalence of ART default and factors associated with ART default among PLWHA in the Ayder Referral Hospital, Mekelle University, Tigray.

\section{Material and methods}

\section{Description of the study area}

The study was carried out among PLWHA eligible for ART medication at the Ayder Referral Hospital, Mekelle,
Tigray, Ethiopia. Ayder hospital provides both an academic and referral center for the dwellers of Mekelle and neighboring town in North Ethiopia. The hospital have launched ART treatment in February 2009. It provides charge-free ART services for those who are eligible to start ART medication based on their CD4 level (patients having $300 \mathrm{CD} 4 / \mathrm{mm}^{3}$ or below). Patients who have been enlisted at the register since February 2009 were involved in this study.

\section{Study design and sampling techniques}

Retrospective cohort study was conducted at the Ayder Referral Hospital, Mekelle, Ethiopia. In total, 240 retrospectively registered PLWHA receiving ART services at the hospital from February 2009 to February 2011 were enrolled into the study. Purposive sampling was employed to select a defaulter as per the operational definition of "default" applied in the study. The term "defaulter" was defined as a PLWHA who failed to take the medication two or more times in a single clinical appointment, including those who refused to return to collect ART medication for two or more appointments starting from February 2009.

\section{Collection of data on the status of ART use among PLWHA}

The hospital's "HIV care/ART follow-up document" was reviewed to establish the status of ART use among the retrospectively registered PLWHA receiving ART services at the hospital. Data were retrieved with the aid of the "Data techniques and information officer", "Adherence support", and "Clinical specialist" together with the investigator.

\section{Collection of socio-demographic profile of the study participants}

Socio-demographic and behavioral data that could be related to defaulting were recovered from ART clinic patients' files, which were recorded from the beginning of treatment. The card included patient's socio-demographic information, disclosure status, past medical status, concern of adherence, and treatment factors.

\section{Data on factors associated with ART default}

Data on factors associated with treatment defaulting were collected using a semi-structured interview. Weekly meeting with 26 respondents was conducted for five subsequent meetings starting from March till April 2011. To obtain the view of the target population, in-depth interviews were conducted with the study participants in ART clinic office, and data were retrieved until reached a point of redundancy of information. Data were also gathered during telephone conversations with 
Table 1. Status of antiretroviral therapy use among HIV-positive individuals in the Ayder Referral Hospital, Mekelle University, Tigray, Ethiopia

\begin{tabular}{l|c|c|c|c}
\hline Status & Male & Female & Total & Percentage (\%) \\
\hline Defaulted & 26 & 32 & 58 & 24.16 \\
\hline Dead & 10 & 12 & 22 & 9.16 \\
\hline Active art users & 92 & 68 & 160 & 66.6 \\
\hline Total & 136 & 104 & 240 & 100 \\
\hline
\end{tabular}

eight informants, with the help of "Adherence support team" who provides a door-to-door support.

\section{Data analysis}

Data on socio-demographic profile of the patients, status of ART use among retrospectively registered clients, and reasons for defaulting treatment were presented using simple descriptive statistics.

\section{Results}

\section{Status of ART use among the patients}

Of the 240 ART patients, 160 (66.6\%) were active ART users, $58(24.16 \%)$ had defaulted the treatment, while $22(9.16 \%)$ had died (Table 1).

\section{Socio demographic characteristic of the defaulters}

Table 2 indicates the socio-demographic data of 58 individuals who had defaulted ART medication. Of these, 54\% were females, younger than 15-year-old (12\%). Most of the respondents were recently married (60\%), unemployed (68\%), orthodox (95\%), aged between $25-34$ years $(44 \%)$, with primary education and living outside the town (60\%).

\section{Factors associated with ART default}

Among the 58 defaulters, 46 (79\%) were traced, and 13 factors associated with ART default were revealed by the study subjects (Table 3). Out of the 58 defaulters, 12 (21\%) individuals were untraced. The major reasons for unsuccessful tracing of patient were the fact that their medical history sheet had an incorrect address (58.3\%), patients had no permanent house and could not be found during their appointment $(25 \%)$, and their address was not written in the registration document (16.7\%) [2].

\section{Discussion}

The present study showed that the rate of default from ART was $24.16 \%$. About one fourth of the study population had a default from ART medication. This rate of default was
Table 2. Socio-demographic characteristics of defaulters from February 2009 to February 2011 in the Ayder Referral Hospital, Mekelle University, Tigray, Ethiopia

\begin{tabular}{|c|c|c|}
\hline Variables & Number & Percentage (\%) \\
\hline \multicolumn{3}{|l|}{ Gender } \\
\hline Female & 31 & 54 \\
\hline Male & 26 & 46 \\
\hline \multicolumn{3}{|l|}{ Age } \\
\hline $15-24$ & 7 & 12 \\
\hline $25-34$ & 25 & 44 \\
\hline $35-44$ & 20 & 35 \\
\hline $45-54$ & 3 & 5 \\
\hline$>55$ & 3 & 5 \\
\hline \multicolumn{3}{|l|}{ Marital status } \\
\hline Single & 9 & 16 \\
\hline Married & 35 & 60 \\
\hline Separated & 9 & 16 \\
\hline Divorce & 3 & 4 \\
\hline Widowed & 3 & 4 \\
\hline \multicolumn{3}{|l|}{ Level of education } \\
\hline No formal education & 14 & 24 \\
\hline Primary education & 21 & 36 \\
\hline Secondary education & 19 & 32 \\
\hline Post-secondary education & 7 & 12 \\
\hline \multicolumn{3}{|l|}{ Religion } \\
\hline Christian orthodox & 55 & 95 \\
\hline Muslim & 3 & 5 \\
\hline \multicolumn{3}{|l|}{ Residence } \\
\hline Out of Mekelle & 35 & 60 \\
\hline Mekelle town & 23 & 40 \\
\hline \multicolumn{3}{|l|}{ Employment } \\
\hline Employed & 19 & 32 \\
\hline Unemployed & 39 & 68 \\
\hline Total & 58 & 100 \\
\hline
\end{tabular}

nearly doubled than that reported in Jimma, who reported $13.6 \%$ of default [11]. On the other hand, it was much less than that reported in Nigeria (36\%) [3]. However, considering the severe consequence of default, $24.16 \%$ rate of default 
Table 3. Factors related to antiretroviral treatment default by HIV/AIDS patients in the Ayder Referral Hospital, Mekelle University, Tigray, Ethiopia

\begin{tabular}{l|c|c}
\hline Category & Frequency & Percentage (\%) \\
\hline $\begin{array}{l}\text { Self-referral to other } \\
\text { hospital }\end{array}$ & 8 & 17.3 \\
\hline Lack of food & 8 & 17.3 \\
\hline Social stigma & 6 & 13.0 \\
\hline Holy water & 5 & 10.8 \\
\hline $\begin{array}{l}\text { Loss of interest } \\
\text { in the medication }\end{array}$ & 4 & 8.7 \\
\hline Long distance to ART center & 3 & 6.5 \\
\hline $\begin{array}{l}\text { Addiction due to repeated } \\
\text { alcohol intake }\end{array}$ & 3 & 6.5 \\
\hline $\begin{array}{l}\text { Being bedridden by different } \\
\text { illness }\end{array}$ & 2 & 4.3 \\
\hline Hard drug abuse & 2 & 4.3 \\
\hline Mental illness & 2 & 4.3 \\
\hline Imprisoned & 1 & 2.3 \\
\hline Felt better & 1 & 2.3 \\
\hline Having HIV-negative partner & 1 & 2.3 \\
\hline
\end{tabular}

cannot be underestimated. Moreover, restarting the medication requires a second-line treatment and highly active antiretroviral therapy (HAART) that needs an excellent degree of drug adherence, and is often associated with lipodystrophy (LD) syndromes characterized by changes in body fat redistribution and insulin resistance, hyperglycemia, diabetes type 2 , hypertriglyceridemia, and hyperlipidemia $[5,20]$.

The commonest (17.3\%) reasons for a default were self-referral to other ART sites and lack of food. Self-referral to other ART center appears to be a means, by which patients use to trick ART adhere support team and their selves at most. Therefore, ART clinics should make sure if the patients have signed a legal transfer from their destiny hospital or ART center, to which they are transferred. Lack of food is even more serious challenge hindering patients not to follow the doses' regimen at the prescribed time. Hence, ART clinics should inform about such issues the concerned bodies timely to ensure food security for PLWHA, thereby reduce the rate of default. Target HIV-impact mitigation programs on poorer households are warranted, as poor households are more likely to experience AIDS-related death and are more vulnerable to socio-economic impact of death [21].

Discloser status of the patient is an important problem, which is likely associated with social stigma, a driving force for patients to hide themselves and eventually, lead to treatment default. This finding is in line with other studies [2-4], where psycho-social factors unrelated to the treatment regimen are major factors for default. Besides, geographical distance, long waiting lines, and being away from home have also been reported to be key barriers to accessibility and adherence to ART [8].

Factors, including alcohol addiction and hard drugs intake were associated with defaulting, thus permitting the patients to delay routine medication use and diminish their judgment about the medication. Similar finding has been reported earlier [16]. Therefore, periodic counseling and treatment for alcohol and drug abuse may contribute to long-term adherence to ART.

Social stigma, holy watering, loss of interest in medication, and imprisoning were associated with long-term defaulting from ART medications. On the other hand, lack of food, being bedridden, long distance to ART site, being addicted to alcohol and drugs, were shown to be associated with short-term defaulting from ART.

The main reason for unsuccessful tracing (21\%) was an incorrect address intentionally given by PLWHA to hide their status. This report is in line with a study from Sagamu, Nigeria [3] that reported untraceable home address or name (5\%). Nevertheless, this is much less than what was reported by Jimma, Ethiopia (61.6\%) [11]. Therefore, improving sincere registration of patients' addresses is necessary because it would facilitate successful tracing in case of patient's lost to follow-up. This may be due to the fact that PLWHA usually do not have a permanent house, rather they prefer to live in various places, in a rented house, in order to keep themselves from publicity. They are prone to shift their residence where they are strangers. A study on HIV testing and ART retention in Ethiopia indicated that irrespective of ART service increase, linkage and retention were not adequate [4]. Therefore, periodic update of every patient's address as well as strategies to improve retention of patients should be developed and implemented to ensure adherence to ART treatment.

This study clearly shows that an ART center must ensure candid registration of patients' addresses. Periodic, home-based adherence support and counseling efforts need be extended to reduce the rate of ART default. Adherence rate and support measures employed should be re-examined to identify adherence strategies that can improve patients' treatment outcomes. A study from Trinidad and Tobago demonstrated that a patient tracing programme through focused tracking activities with dedicated staff to be feasible for re-engaging those patients who were lost to follow-up (LTFU). This serves as a primary prevention tool before patients' defaults treatments, therefore reducing the risk of developing complications and expansion of resistive strains of the virus [22]. Visual analogue scale (VAS), pill identification test (PIT), and health center-based pill counts might help to monitor adherence among HIV/AIDS ART patients [14]. The adherence supporter team has been reported to be a practical and feasible tool for improving adherence, as proven to achieve more than four times the odds of attaining optimal adherence in Uganda [15]. Expert patients, patients who have overcame the stigma, and those with good experience of ART adherence, should be encouraged to share their success stories in adhering to ART with other patients, causing good energy to positively inspire defaulters [2]. 


\section{Conclusions}

About one fourth of PLWHA defaulted from ART treatment in the Ayder Referral Hospital, Mekelle University. This was primarily due to self-referral to other hospitals, lack of food, social stigma, holy water, and loss of interest in medication. The study highlights that economic and social factors are the root of all reasons associated with default from ART treatment. Employing intensive patients' tracing activities with health extension groups, or non-professional adherence support team, can help to achieve adherence rates greater than 95\%. Moreover, providing a platform through establishing of ART adherence support team composed of PLWHA to support each other, might enable sharing experiences between active ART users and new patients in order to support the reduction of defaulters' rate. Also, economic empowerment for PLWHA would be helpful to alleviate the intermittent defaulting.

\section{Ethics approval and consent to participate}

Letters of permission was gained from the College of Natural and Computational Science and College of Health Science, Mekelle University. The participants were allowed to consider their participation and given the opportunity to withdraw from the study at any point in the course of the study.

\section{Acknowledgement}

The author would like to thank Sister Mitslal, Mrs Amit, Mrs Abeba, Mr Hagos, and to all staff from ART clinics at the Ayder Referral Hospital for their cooperation. Many thanks also to Mr. Naodd Gebresamuel from the Department of Pharmacy, Mekelle University.

\section{Conflict of interest}

The authors declare no conflict of interest with respect to the research, authorship, and/or publication of this article.

\section{References}

1. Deribew A, Biadgilign S, Deribe K, et al. The burden of HIV/AIDS in Ethiopia from 1990 to 2016: evidence from the Global Burden of Diseases 2016 Study. Ethiop J Health Sci 2019; 29: 859-868.

2. Kahema SE, Mgabo MR, Emidi B, Sigalla GN, Kajeguka DC. Factors influencing adherence to antiretroviral therapy among HIV infected patients in Nyamagana-Mwanza, Northern Tanzania: a cross sectional study. Int J Med Microbiol 2018; doi: doi.org/10.23937/ iamm-2017/1710002.

3. Daniel OJ, Oladapo OT, Ogundahunsi OA, Fagbenro S, Ogun SA, Odusoga OA. Default from anti-retroviral treatment programme in Sagamu, Nigeria. African Journal of Biomedical Research 2008; 11 : 221-224.

4. Assefa Y, Van Damme W, Mariam DH, Kloos H. Toward universal access to HIV counseling and testing and antiretroviral treatment in Ethiopia: looking beyond HIV testing and ART initiation. AIDS Patient Care STDs 2010; 24: 521-525.
5. Jain RG, Furfine ES, Pedneault L, White AJ, Lenhard JM. Metabolic complications associated with antiretroviral therapy. Antiviral Res 2001; 51: 151-177.

6. Semvua SK, Orrell C, Mmbaga BT, Semvua HH, Bartlett JA, Boulle AA. Predictors of non-adherence to antiretroviral therapy among HIV infected patients in northern Tanzania. PLoS One 2017; 12: e0189460.

7. Tesfaye T, Darega J, Belachew T, Abera A. Health-related quality of life and associated factors among people living with HIV/AIDS following ART clinic in Jimma University Specialized Hospital, Southwest Ethiopia: a facility-based cross-sectional study. The Open Public Health Journal 2018; 11: 572-583.

8. Kloos H, Assefa Y, Hailemariam D, Mulatu MS, Converse P. Bibliography on HIV/AIDS in Ethiopia and Ethiopians in the Diaspora: the 2007 update, with an emphasis on the ART scale-up. The Ethiopian Journal of Health Development (EJHD) 2008; 22.

9. Estill J, Ford N, Salazar-Vizcaya L, et al. The need for second-line antiretroviral therapy in adults in sub-Saharan Africa up to 2030: a mathematical modelling study. Lancet HIV 2016; 3: e132-e139.

10. Amico KR, Harman JJ, Johnson BT. Efficacy of antiretroviral therapy adherence interventions: a research synthesis of trials, 1996 to 2004. J Acquir Immune Defic Syndr 2006; 41: 285-297.

11. Deribe K, Hailekiros F, Biadgilign S, Amberbir S, Beyene BK. Defaulters from antiretroviral treatment in jimma university specialized hospital, Southwest Ethiopia. Trop Med Int Health 2008; 13: 328-333.

12. Yimer YT, Yalew AW. Magnitude and predictors of anti-retroviral treatment (ART) failure in private health facilities in Addis Ababa, Ethiopia. PLoS One 2015; 10: e0126026.

13. Ahmed MM, Merga $H$, Jarso $H$. Predictors of virological treatment failure among adult HIV patients on first-line antiretroviral therapy in Woldia and Dessie hospitals, Northeast Ethiopia: a case-control study. BMC Infect Dis 2019; 19: 305

14. Chirundu D, Magande PN, Tapesana S, Mduluza T. Adherence to antiretroviral therapy among clients utilizing a primary health care facility Kadoma Zimbabwe (2016). Texila International Journal of Nursing 2018; 4.

15. Kunutsor S, Walley J, Katabira E, et al. Improving clinic attendance and adherence to antiretroviral therapy through a treatment supporter intervention in Uganda: a randomized controlled trial. AIDS Behav 2011; 15: 1795-1802.

16. Chesney MA. Factors affecting adherence to antiretroviral therapy. Clin Infect Dis 2000; 30 Suppl 2: S171-S176.

17. Duke N, Aboh S, Bosivert N. Analysis of resistance testing in South Trinidad. West Indian Med J 2010; 59: 400-402.

18. Shigdel R, Klouman E, Bhandari A, Ahmed LA. Factors associated with adherence to antiretroviral therapy in HIV-infected patients in Kathmandu District, Nepal. HIV/AIDS (Auckl) 2014; 6: 109116.

19. Obirikorang Ch, Selleh PK, Abledu JK, Fofie ChO. Predictors of adherence to antiretroviral therapy among HIV/AIDS patients in the Upper West Region of Ghana. ISRN AIDS 2013; 2013: 873939.

20. Olczak A. Metabolic disturbances associated with HAART. Przeglad Epidemiologiczny 2007; 61: 639-646.

21. Tekola F, Reniers G, Haile Mariam D, Araya T, Davey G. The economic impact of HIV/AIDS morbidity and mortality on households in Addis Ababa, Ethiopia. AIDS Care 2008; 20: 995-1001.

22. Edwards RJ, Lyons N, Bhatt Ch, Samaroo-Francis W, Hinds A, Cyrus $\mathrm{E}$. Implementation and outcomes of a patient tracing programme for HIV in Trinidad and Tobago. Glob Public Health 2019; 14: 1589-1597. 